\title{
Assessing fine-scale diel movement patterns of an exploited coral reef fish
}

\author{
Leanne M. Currey ${ }^{1,2,3^{*}}$, Michelle R. Heupel ${ }^{2,3}$, Colin A. Simpfendorfer ${ }^{3}$ and Ashley J. Williams 3,4
}

\begin{abstract}
Background: Understanding movement patterns of species requires that the spatial and temporal scales of experimental designs are appropriate to the proposed ecological questions. Previous research on large-scale movements of the exploited reef fish Lethrinus miniatus suggested that adult individuals may use coral reef slope habitat during the day, shifting to adjacent deeper sandy habitat at night. However, investigation of movement at a fine spatial and temporal scale is required to verify this diel activity pattern. Using a closely positioned acoustic telemetry system, movements of 11 L. miniatus were monitored among habitats from the reef crest, to reef slope and deeper adjacent sandy habitat over 3 months. Fine-scale movement patterns among these habitats were compared among four different $3 \mathrm{~h}$ periods of the day: dawn, day, dusk and night.

Results: Initial observations demonstrated significantly larger horizontal core areas and vertical areas of extent during crepuscular and night periods compared to during the day. Vertical space use (core area and extent) was consistently larger during dawn, dusk and night compared to during the day. Area of activity space extent within the water column and proportional overlap among areas used during different periods of the day varied among weeks, and displayed a pattern consistent with full moon periods.

Conclusions: Although previous evidence suggested that L. miniatus adults may shift to deeper habitats adjacent to the reef slope at night, greater space use across the shallow crest to deeper sand habitat was observed during dawn, dusk and night periods. Increased luminosity during dawn, dusk and night periods may cause L. miniatus to utilise a larger search area for foraging. While further research is required to confirm foraging during the hours of twilight and darkness, this fine-scale approach identified patterns in nocturnal activity for an important reef teleost. Knowledge of these temporal and spatial differences in L. miniatus behaviour and movement are important to understanding how this species coexists within ecological niches.
\end{abstract}

Keywords: Acoustic telemetry, Small-scale, Lethrinidae, Fisheries management

\section{Background}

Reef fishes move over multiple spatial and temporal scales. Understanding the movement ecology of particular species requires study on scales appropriate to the proposed ecological question [1]. Research conducted over large spatial scales $(100 \mathrm{~s}$ of $\mathrm{km})$ and periods of months to years can capture information on ontogenetic movement and spawning migrations of adult

\footnotetext{
*Correspondence: leanne.currey@my.jcu.edu.au

${ }^{3}$ Centre for Sustainable Tropical Fisheries and Aquaculture and College of Marine and Environmental Sciences, James Cook University, Townsville, QLD 4811, Australia

Full list of author information is available at the end of the article
}

populations, while studies encompassing small spatial scales (a few kilometres) and shorter time periods can effectively define activity space use of individuals. Spatial and temporal resolution of the sampling methodology varies with scale, thus, it is necessary to consider these elements in the context of intended research.

Home range or extent of activity space encompasses the majority of the area typically used by individuals during daily routine activities [2]. Daily space use can comprise movements between different habitats used for different functions, and these can be spatially and temporally separated. Reef fishes may traverse shallow reef crests, reef slopes and adjacent sandy habitats during 
different times of the day, and their activity is largely regulated by the diurnal $(24 \mathrm{~h}$ ) cycle of the sun rising and setting [3]. Use of different habitats during different times of day may help fulfil biological and ecological needs such as foraging, predator avoidance and resting [4].These movement patterns are typical of Haemulids, which rest during the day among coral reefs and move along consistent routes to adjacent sandy habitats at night to forage [5]. Carangids also display a pattern of roaming the reef crest at night, using different foraging areas and displaying greater activity during daylight hours [6]. In contrast, diurnal scarids actively forage along the reef during daylight hours and rest inside mucous cocoons in crevices within these areas at night [7]. It appears that benefits are gained through use of different habitats at different times of the day for resting and feeding with movement between areas rich in specific resources (e.g., shelter, prey).

Recent tracking research on the space use of a tropical species, Lethrinus miniatus, hypothesised that lower detection frequency at night was due to movement away from the reef slope into the adjacent sandy habitat to forage [8]. This hypothesis is consistent with the documented ecology of L. miniatus, as a nocturnal predator of crustaceans and echinoderms [9]. Currey et al. [8] reached their hypothesis based on monitoring large-scale movement of adult individuals using a line of acoustic receivers parallel to the reef crest. Movement patterns of $L$. miniatus are not well understood and the resulting hypothesis of movement away from the reef crest at night could not be answered with the large-scale approach applied. This raises the questions: does space use of $L$. miniatus differ at different times of the day across habitats, and is use of these areas consistent through time? Individuals might utilise deeper areas off the reef crest for foraging during the night, while using shallower reef habitat during the day for resting. To test the Currey et al. [8] hypothesis, a fine-scale acoustic tracking approach that included reef crest, slope and adjacent sandy habitats was applied to the same population of $L$. miniatus.

The aim of this study was to determine whether diel differences in space use and distance from the reef crest were apparent in adult $L$. miniatus. Data were also used to identify whether the same areas and habitat types were used consistently over multiple months. Using an array of closely positioned acoustic receivers between reef crest and adjacent sand habitats, fine-scale horizontal and vertical space use was examined during different periods of the day and among weeks to identify the amount of overlap and reuse of these areas. Fine-scale data provided insight into diel activity to better define the variation in movement patterns observed for L. miniatus in other studies.

\section{Results}

Of the eleven L. miniatus fitted with acoustic transmitters, seven were detected over 93 days of monitoring between 22 March and 22 June 2014 (Table 1). The majority of these individuals (five) were detected consistently across the monitoring period and provided sufficient positions for inclusion in analyses. The other four individuals were excluded from the analysis because their detection profiles suggested they had perished. Detections varied among the four time periods of dawn, day, dusk and night, with more detections of individuals during daylight hours. Standardisation of detections based on sentinel tag data indicated that absence during crepuscular (dawn and dusk) and night periods was not an artefact of transmitter detectability.

\section{Horizontal space use}

Tagged individuals occupied horizontal space across a number of receivers, including stations located on both inner and outer receiver lines (Fig. 1) indicating use of reef crest, slope and sandy habitats. In general, the location of daytime horizontal kernel utilisation distributions (hKUDs) were different to hKUDs for dawn, dusk and night periods. Specifically, core use areas (50 \% hKUDs) were significantly larger for dawn, dusk and night periods than the core use areas during day periods (Table 2; Fig. 2a). Dawn, dusk and night core use areas were also more broadly distributed between inner and outer receivers compared to day periods (e.g. Fig. 1a, b). Mixed effects models illustrated an overall trend in lower mean activity space for day periods, despite variation in 50 and $95 \%$ hKUD size estimates (Fig. 2a, b). Fish size was not a significant factor in horizontal space use (Table 2).

Activity space extent (95 \% hKUDs) during dawn, dusk and night periods was not significantly greater compared to during the day (Table 2; Fig. 2b). Greater variability was observed in $95 \%$ hKUD for individual 10168

Table 1 Details of Lethrinus miniatus monitored at Heron Island Reef

\begin{tabular}{llllr}
\hline Individual & FL & Date released & Last detection & COAs \\
\hline 10154 & 435 & $23 / 03 / 2014$ & $22 / 06 / 2014$ & 7994 \\
10155 & 464 & $22 / 03 / 2014$ & $22 / 06 / 2014$ & 10,056 \\
10158 & 421 & $23 / 03 / 2014$ & $3 / 05 / 2014$ & 115 \\
10162 & 410 & $23 / 03 / 2014$ & $22 / 06 / 2014$ & 9964 \\
10164 & 388 & $22 / 03 / 2014$ & $26 / 03 / 2014$ & 171 \\
10168 & 376 & $23 / 03 / 2014$ & $22 / 06 / 2014$ & 1634 \\
10170 & 415 & $22 / 03 / 2014$ & $22 / 06 / 2014$ & 9471 \\
\hline
\end{tabular}

Individual L. miniatus were monitored from 22 March 2014 to 22 June 2014. FL refers to the size of the individual (fork length), and COAs are the number of centre of activity estimates obtained during the monitoring period 


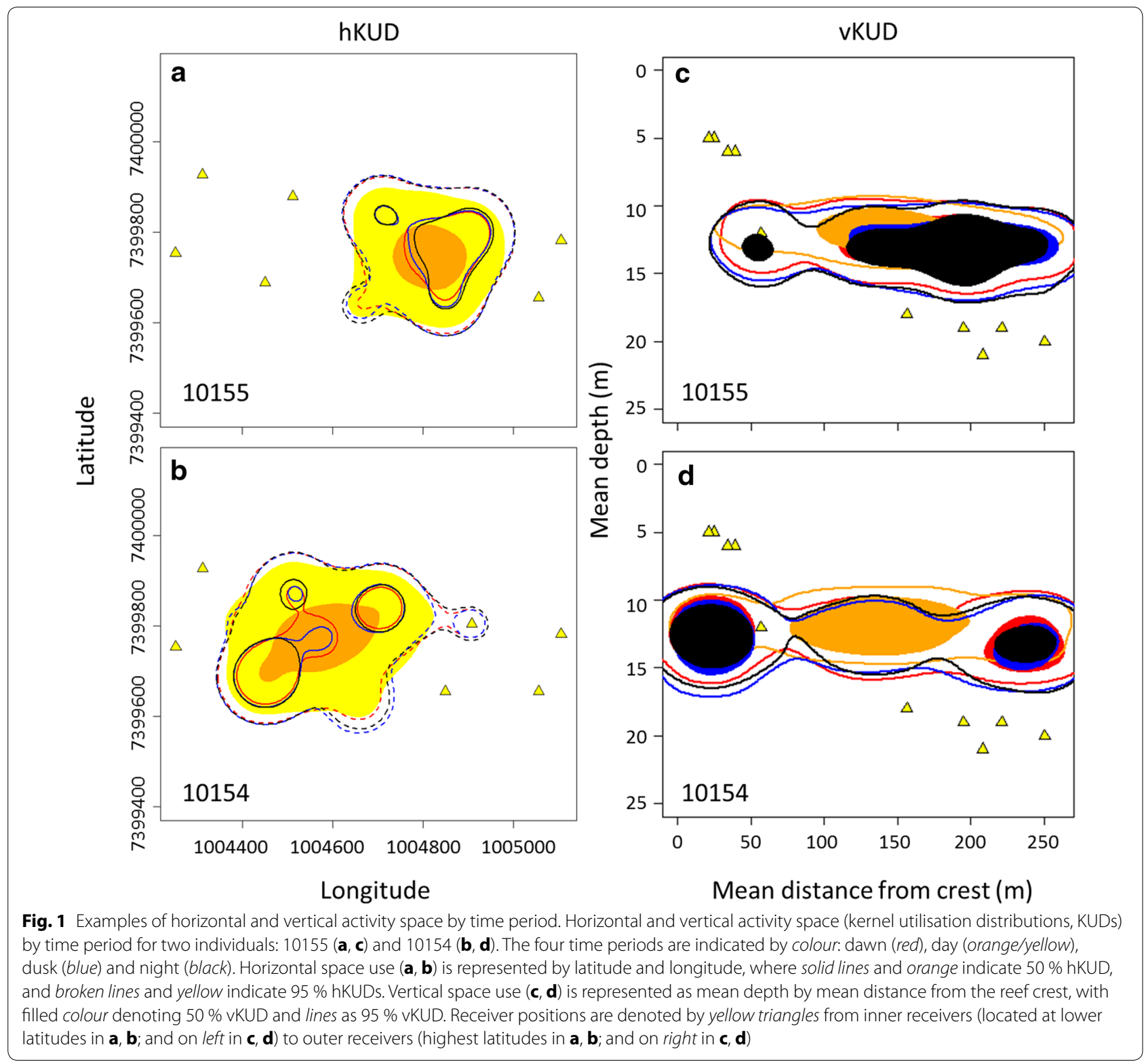

(and lower $50 \%$ hKUD) which was likely due to the home range of this individual straddling the boundary of the monitored area, meaning space use would have been underestimated.

\section{Vertical space use}

Patterns in vertical space use were similar among individuals. Similar to hKUDs, vertical kernel utilisation distributions (vKUDs) illustrated clear differences between periods, with day contrasting dawn, dusk and night periods. Core space use during the day was concentrated among the middle of the reef slope, compared to dawn, dusk and night core areas which were spread among all receivers (e.g., Fig. 1c, d). Vertical core area was not significantly different among periods (Table 2; Fig. 2c). Core depth use was often shallower during the day, however, depth use overall was consistent among individuals (c. 10-15 m). In contrast, activity space extent was significantly larger during dawn, dusk and night periods than during the day (Table 2; Fig. 2d), illustrating the nocturnal habits of this species.

Overlap in daytime vertical space use with dawn, dusk and night periods revealed significant differences for core (50\% vKUD) estimates (mixed effects model, $\mathrm{F}=11.029$, $\mathrm{df}=5, p<0.001$ ), but not for extent of movement (95\% vKUD) estimates (mixed effects model, $\mathrm{F}=2.628$, 
Table 2 Model results for activity space among time periods

\begin{tabular}{lllll}
\hline & $\mathbf{5 0} \%$ hKUD & $\mathbf{9 5} \%$ hKUD & $\mathbf{5 0} \%$ vKUD & $\mathbf{9 5} \%$ vKUD \\
\hline Day vs dawn & 0.006 & 0.085 & 0.064 & $<0.001$ \\
Day vs dusk & 0.001 & 0.493 & 0.092 & $<0.001$ \\
Day vs night & 0.002 & 0.565 & 0.190 & 0.001 \\
Dawn vs dusk & 0.410 & 0.263 & 0.842 & 0.692 \\
Dawn vs night & 0.496 & 0.222 & 0.529 & 0.411 \\
Dusk vs night & 0.882 & 0.910 & 0.665 & 0.232 \\
FL & 0.131 & 0.922 & 0.141 & 0.217 \\
\hline
\end{tabular}

Mixed effects model results ( $p$ values, significant values indicated in italics) for horizontal and vertical kernel utilisation distributions (KUDs), comparing among time periods (dawn, day, dusk and night) and individual size (fork length, FL). All models included individual as a random effects term $\mathrm{df}=5, p=0.067)$. Overlap was lowest for day periods, and average core areas comprised $37 \%$ of the area used at dawn, $29 \%$ at dusk and $30 \%$ at night areas. An overlap of $72 \%$ of the core areas was observed between dawn and dusk and dawn and night, and $28 \%$ overlap of dusk and night areas. High overlap was observed across periods for movement extent (77-91 \%). In general, this highlights the greater spread of vertical core areas used during dawn, dusk and night periods.

\section{Vertical activity space by period and week}

Weekly analysis of space use revealed that the significant differences between daytime areas of activity compared with dawn, dusk and night periods were
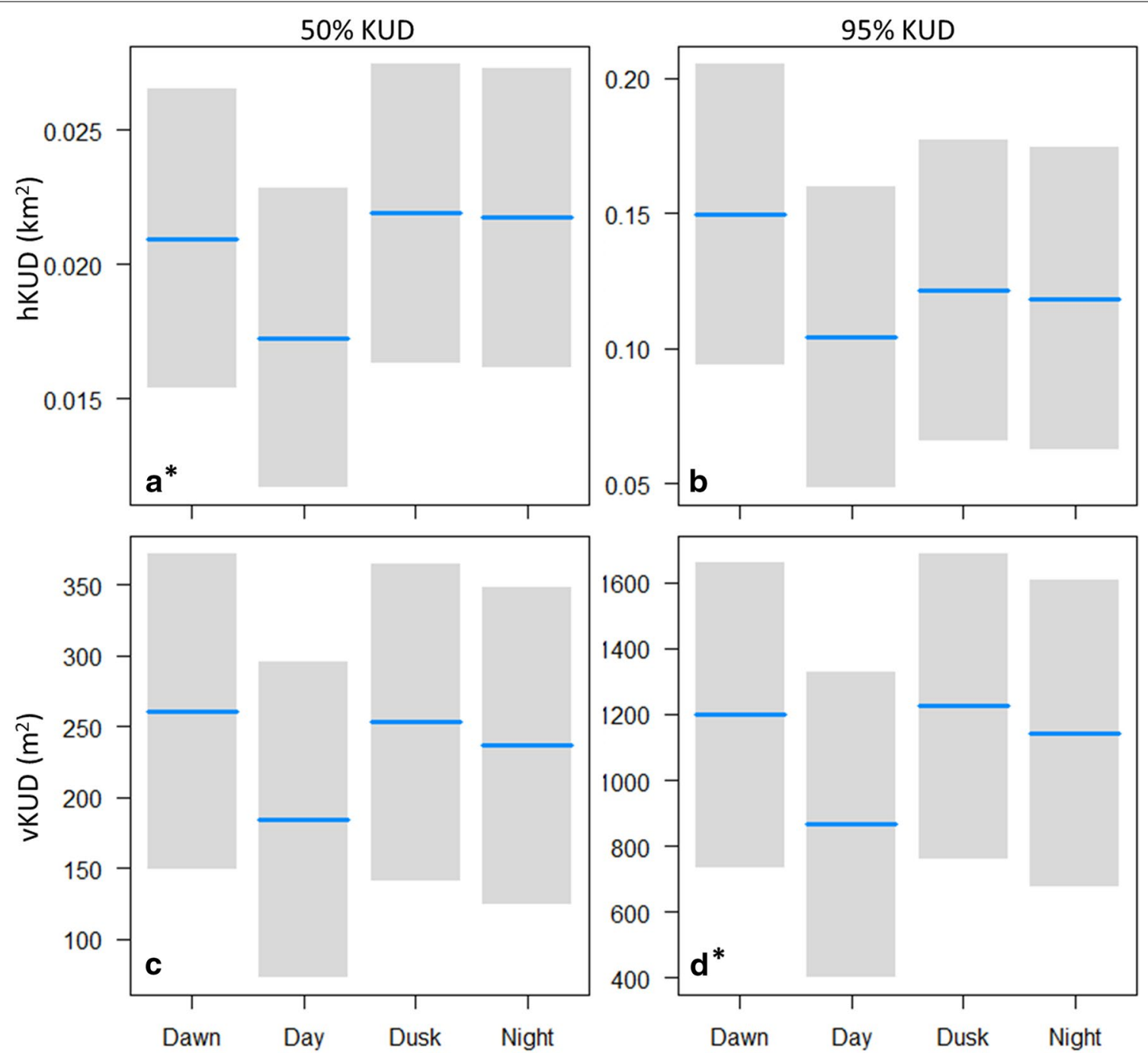

Period

Fig. 2 Model plots of horizontal and vertical activity space by time period. Results from mixed effects models illustrating $50 \%$ (a) and $95 \%$ (b) horizontal kernel utilisation distribution (KUD) area and $50 \%$ (c) and $95 \%$ (d) vertical KUD area by time period (dawn, day, dusk and night). Lines indicate mean KUD, grey shading is the $95 \%$ confident intervals, and asterisks signify significant differences among periods 
consistent through time (Table 3; Figs. 3, 4). Statistically, $95 \%$ vKUDs were dissimilar among dusk and night periods, but overall vertical space use patterns among periods were similar for both 50 and $95 \%$ vKUDs. Extent of activity space was also significantly related to week through the monitoring period (Table 3; Fig. 4c). Activity space extent was significantly influenced by week and the model predicted larger areas within the water column used around weeks 15-16 (14-27 April), 19-20 (12-28 May) and week 24 (23 June; Fig. 4c). Full moon occurred on 15 April (week 15), 15 May (week 19) and 13 June (week 23) during the monitoring period (denoted on Fig. 3).
Percent overlap of activity space was calculated to determine whether activity space included consistent re-use of space across weeks. Estimates of 50 and $95 \%$ vKUD were calculated for each time period (dawn, day, dusk and night) and compared among monitoring weeks. Variation was observed in the overlap of core space use among periods over time, with significant differences in overlap only observed between dusk and night periods (Table 3; Fig. 5a, b). Significant differences were detected among weeks for core and extent of space use (Table 3; Fig. 6a, b). Dawn and day periods followed the same trend with a peak in core space use at week 19, while overlap fluctuated among weeks for dusk and night, with

Table 3 Model results for vertical activity space among time periods by week

\begin{tabular}{|c|c|c|c|c|c|c|}
\hline & \multicolumn{2}{|l|}{ Activity space } & \multicolumn{2}{|c|}{ Percentage overlap } & \multicolumn{2}{|c|}{ Cumulative area } \\
\hline & $50 \%$ vKUD* & $95 \%$ vKUD* & $50 \%$ vKUD $^{x}$ & $95 \%$ vKUD ${ }^{x}$ & $50 \%$ vKUD & $95 \%$ vKUD \\
\hline Day vs dawn & $<0.001$ & $<0.001$ & 0.967 & 0.056 & $<0.001$ & $<0.001$ \\
\hline Day vs dusk & $<0.001$ & $<0.001$ & 0.702 & 0.171 & $<0.001$ & $<0.001$ \\
\hline Day vs night & $<0.001$ & $<0.001$ & 0.053 & 0.183 & $<0.001$ & $<0.001$ \\
\hline Dawn vs dusk & 0.953 & 0.079 & 0.733 & 0.586 & 0.770 & 0.564 \\
\hline Dawn vs night & 0.403 & 0.725 & 0.048 & 0.862 & 0.001 & 0.084 \\
\hline Dusk vs night & 0.438 & 0.036 & $<0.001$ & 0.711 & 0.002 & 0.248 \\
\hline Week & 0.066 & $<0.001$ & $<0.001$ & $<0.001$ & 0.482 & $<0.001$ \\
\hline
\end{tabular}

Results of mixed effects models ( $p$ values, significant values indicated in italics) examining vertical activity space use (kernel utilisation distributions, KUDs) of Lethrinus miniatus by period and monitoring week. Area, percentage overlap and cumulative area by week were calculated for core (50\%) and extent ( $95 \%$ ) of activity space. Week was fitted as a natural spline with varying degrees of freedom (models with $\mathrm{df}=3$ provided best fits to the data for all estimates except $95 \%$ vKUD and $95 \%$ overlap estimates, where $\mathrm{df}=7$ ). Transformations of vKUD are indicated as asterisks (square root transformed) and crosses (arcsine square root transformed)

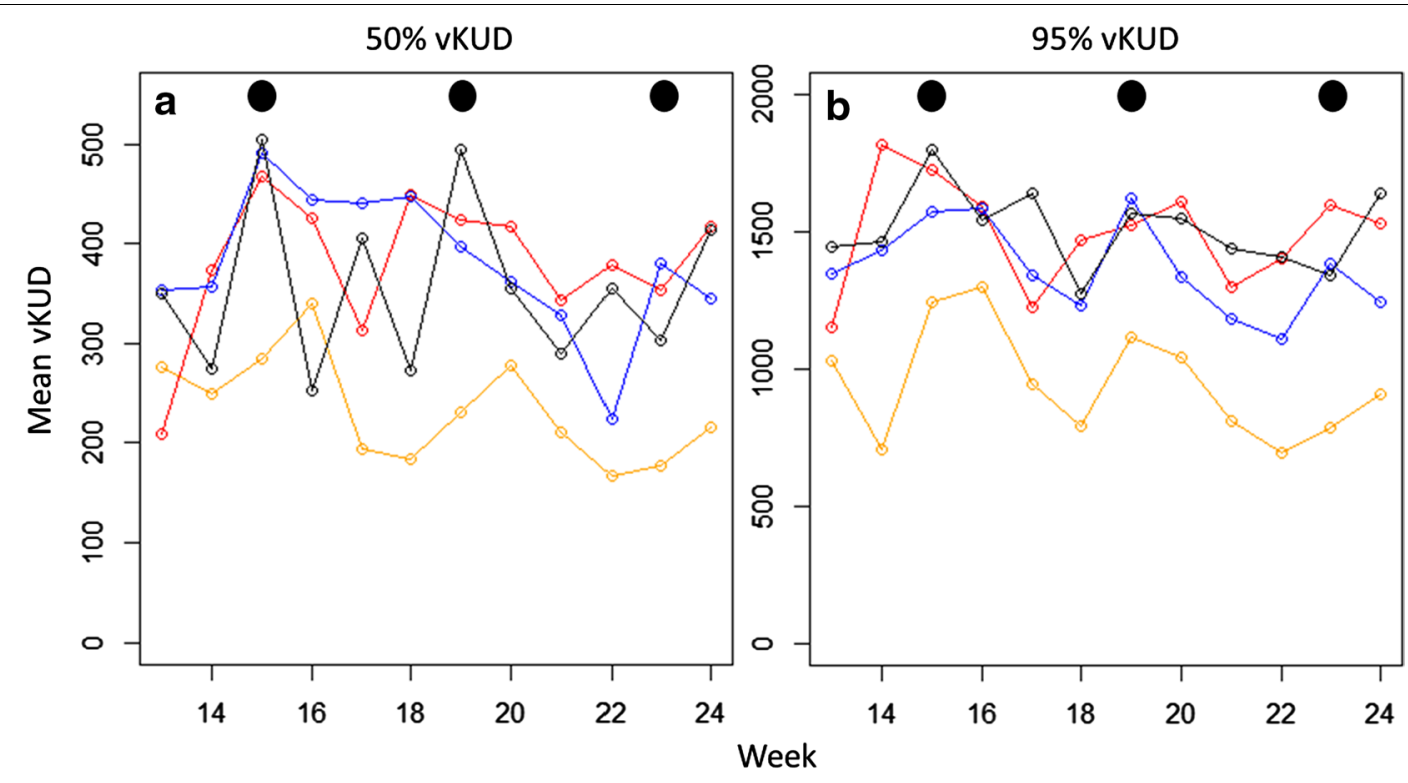

Fig. 3 Mean vertical activity space by period and week. Mean $50 \%$ (a) and $95 \%$ (b) vertical kernel utilisation distributions (vKUD) by period and week. The four time periods are indicated by colour: dawn (red), day (orange), dusk (blue) and night (black). Filled circles represent full moon weeks 


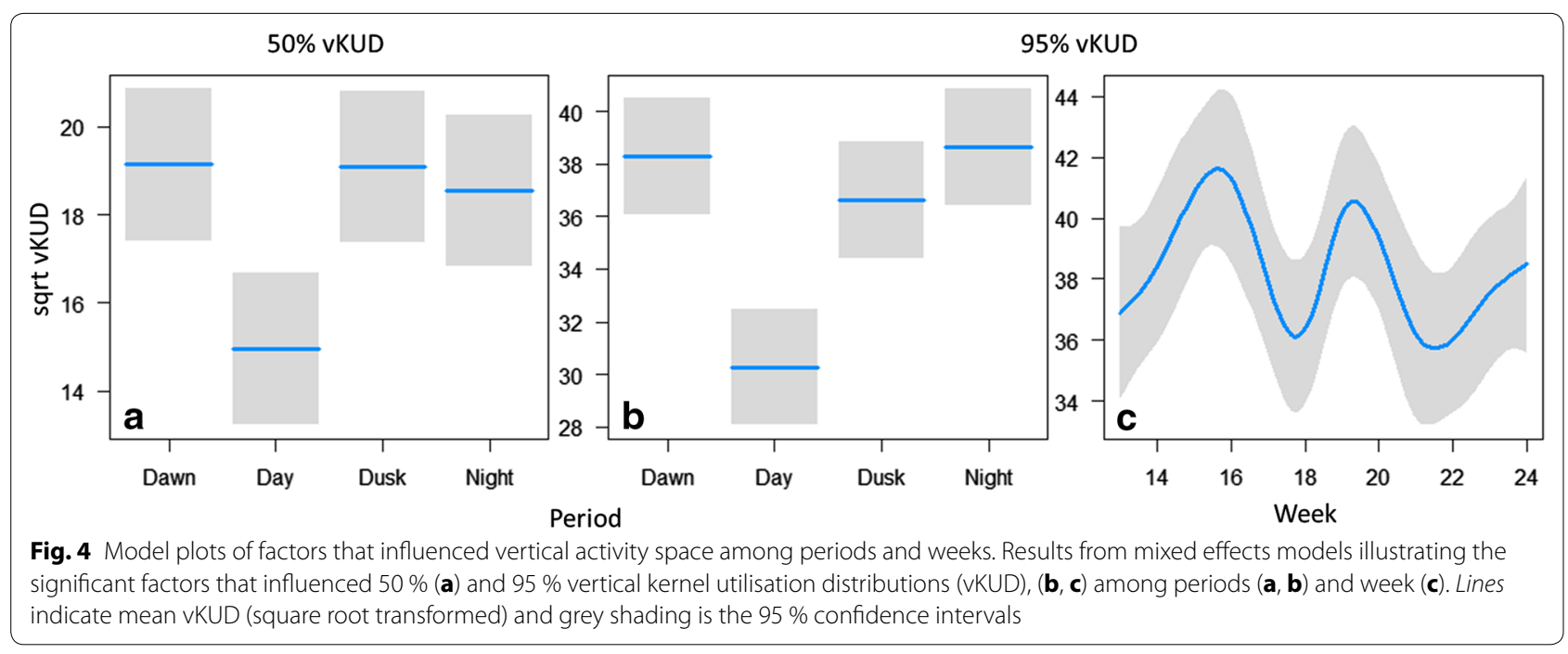

night overlap ranging between 50 and $90 \%$ between successive weeks (Fig. 5a). Following week 22 (8 June), overlap decreased for all periods, signifying core activity shifted to using different areas for the final two weeks of monitoring (Fig. 5a). An n-shaped pattern was observed for percent overlap of core areas by model results, with a peak in overlap between weeks 18-20 (28 April-25 May) decreasing thereafter (Fig. 6a).

Overlap of home range extent was consistently high through time and ranged between 80 and $100 \%$ from week to week for each period (Fig. 5b). Model results (best-fitting model included week fitted as a natural spline with $\mathrm{df}=7$ ) indicated the overlap of mean space use extent fluctuated among weeks, with greater overlap around weeks 15, 19 and 23, corresponding to full moon periods (Fig. 6b).

While percent overlap provided an estimate of the area used among weeks, extrapolating as to whether the area of space use increased with time was achieved by calculating the cumulative 50 and $95 \%$ vertical KUDs. Patterns in space use were similar (non-significant) among crepuscular periods (dawn and dusk) for core and extent

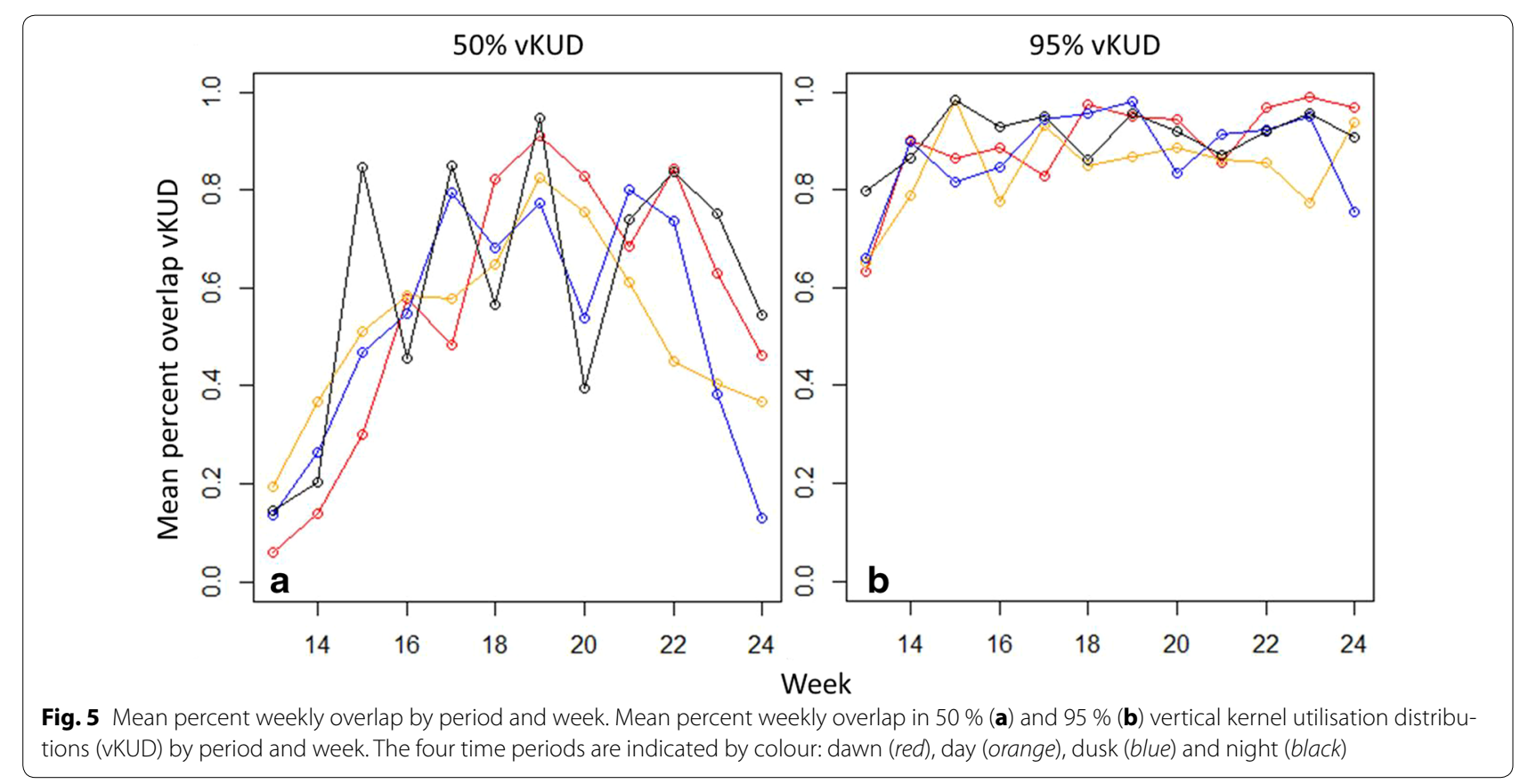




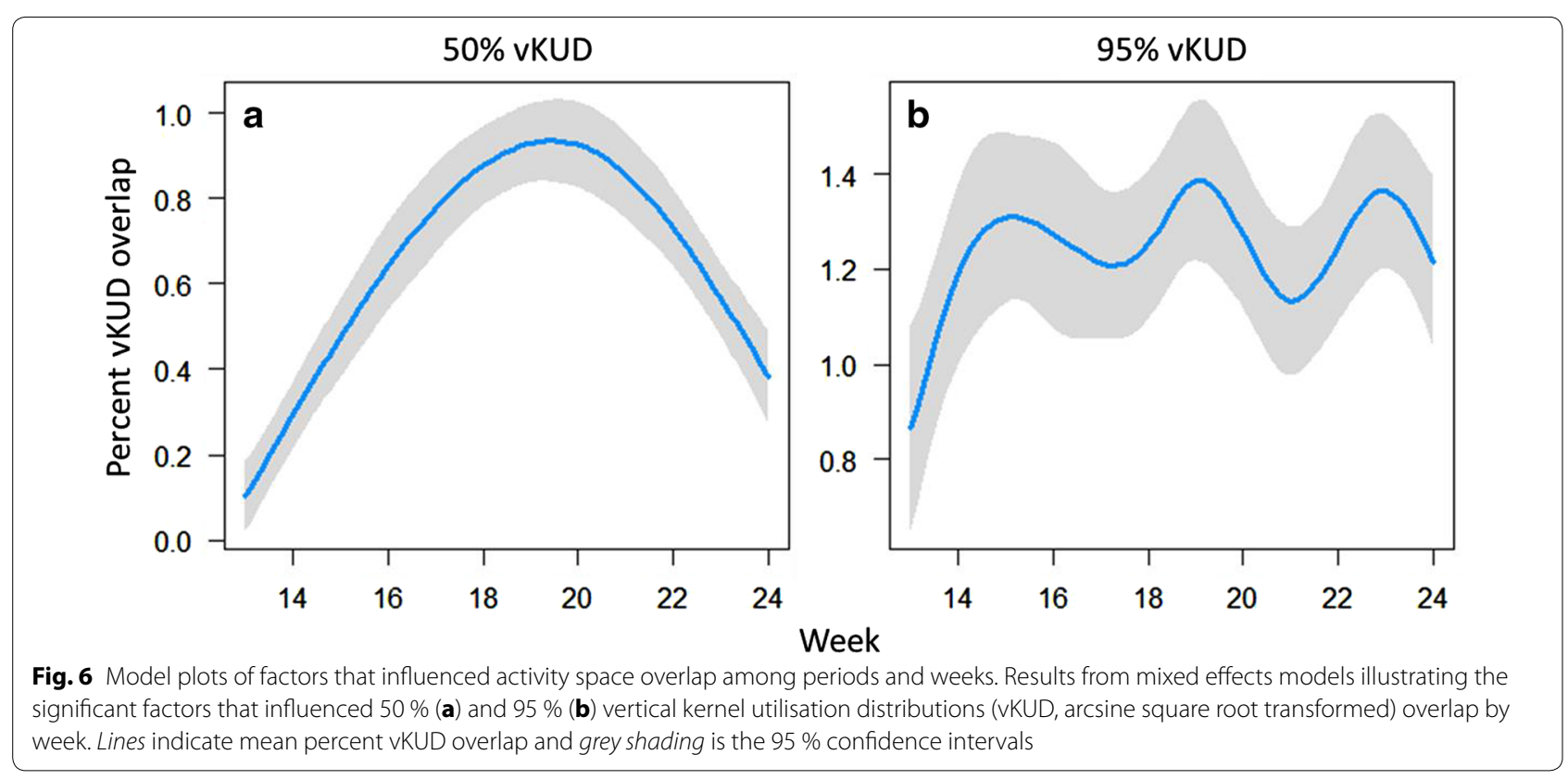

areas, becoming relatively stable after the third week of monitoring (week 16; Fig. 7a, b; Table 3). Night time core space use of individuals showed an overall increasing trend with time, while the extent of movement peaked later than day time and crepuscular periods. Cumulative space use during the day was consistently lower than all other periods. Significant differences were revealed among weeks for $95 \%$ vKUDs (Table 3; Fig. 8c), however confidence bands were broad, indicating variation in the data. Separation between daytime and crepuscular/ night periods, were further highlighted by $95 \%$ vKUDs (Figs. 7b, 8b). Core areas were not only larger in cumulative area for crepuscular and night periods compared to day, but there was also greater area used during crepuscular periods overall (Fig. 7a; Table 3).

\section{Discussion}

Fine-scale telemetry data illustrated differences in space use of L. miniatus during different periods of the day. Fewer detections of this species on the reef slope at night documented by Currey et al. [8] was hypothesised to reflect dispersal away from daytime areas on the reef slope to deeper sandy areas at night. Application of an expanded fine-scale telemetry array revealed that horizontal core use areas and vertical extent of activity space were significantly smaller during the day compared to dawn, dusk and night periods, with the latter likely comprising space beyond the outer sandy area detection range. When examined on a weekly basis, this diel pattern was stronger for vertical space use, corresponding with a lifestyle of nocturnal mobility and foraging behaviour [10]. Individual core areas varied in size, and re-use through time, while overlap differed through time. Day time extent of activity space was also smaller in area compared to other times of the day and, over time, appeared to be linked to lunar phase. Fine-scale analysis of movement patterns revealed more detail about the habitats exploited by this species and the consistency of their use through time, increasing our understanding of the movement ecology of L. miniatus.

Diel patterns in activity are common for many coral reef fishes [11-13]. With most fishes being either diurnal or nocturnal, a complex sequence of events occurs on coral reefs during dusk and dawn transition periods [3]. Patterns in daily activity influence how species persist in their environment and adapt to different niches [14]. For nocturnal species, foraging typically occurs during crepuscular and night periods while daylight hours are spent resting or patrolling $[3,15]$. Diurnally active species typically leave night time refuges at dawn to forage, returning to rest at sunset (e.g. $[16,17])$. Crepuscular periods in particular can be advantageous hours for foraging, since low light levels can provide predators with an advantage [18]. Feeding on crustaceans, echinoderms, molluscs and small fish, L. miniatus is known as a nocturnal predator that forages in sandy habitats adjacent to coral reefs, reported to only feed opportunistically during day [9]. This is consistent with recent research that revealed low presence of this species on a reef slope during night hours (1800-0600 h), and a suggested shift to deeper sandy habitats at night [8]. Although the dawn and dusk periods selected in this study comprised portions of 

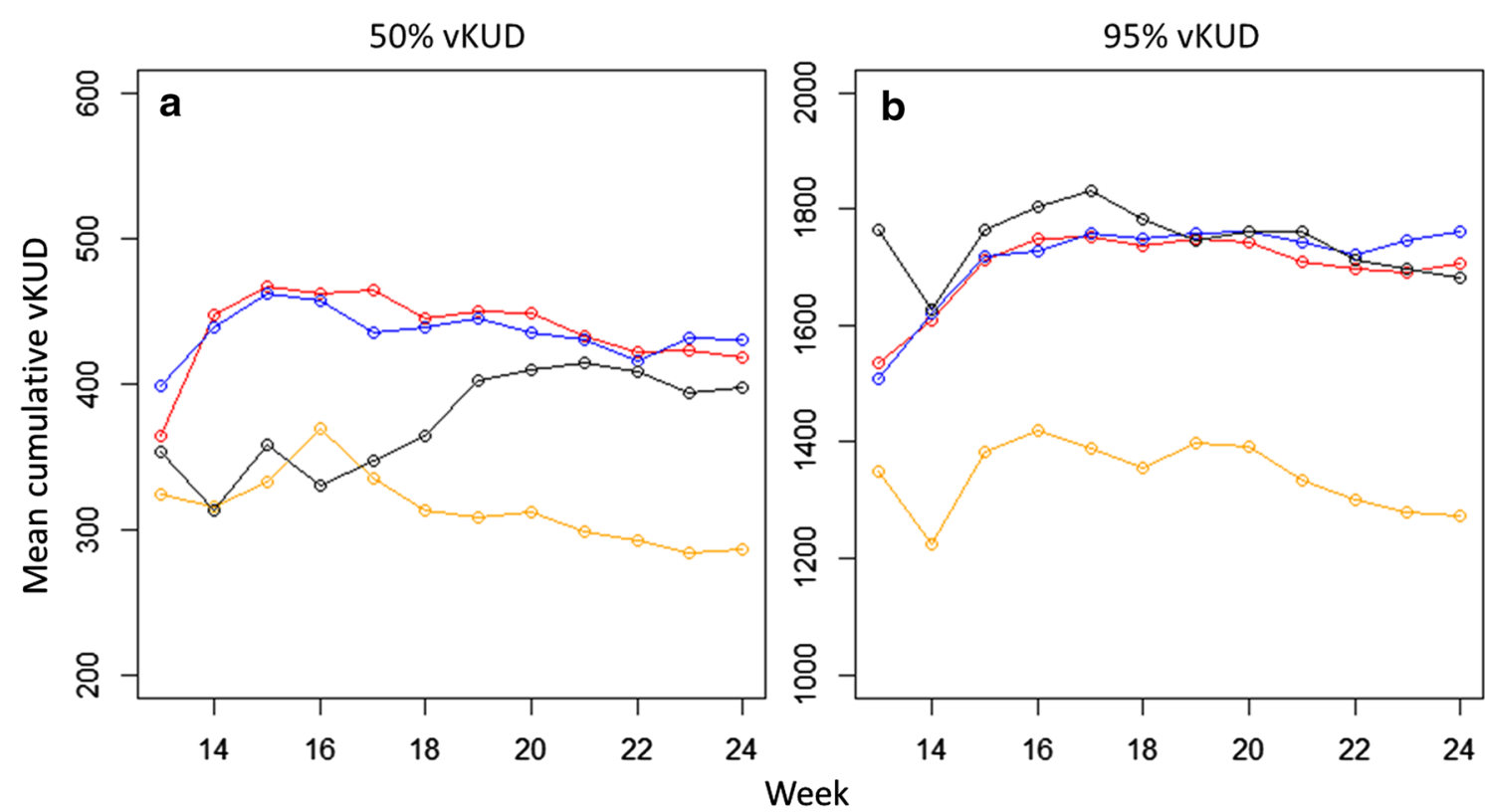

Fig. 7 Mean cumulative vertical space use by period and week. Mean cumulative $50 \%$ (a) and $95 \%$ (b) vertical kernel utilisation distributions (vKUD) by period and week. The four time periods are indicated by colour: dawn (red), day (orange), dusk (blue) and night (black)

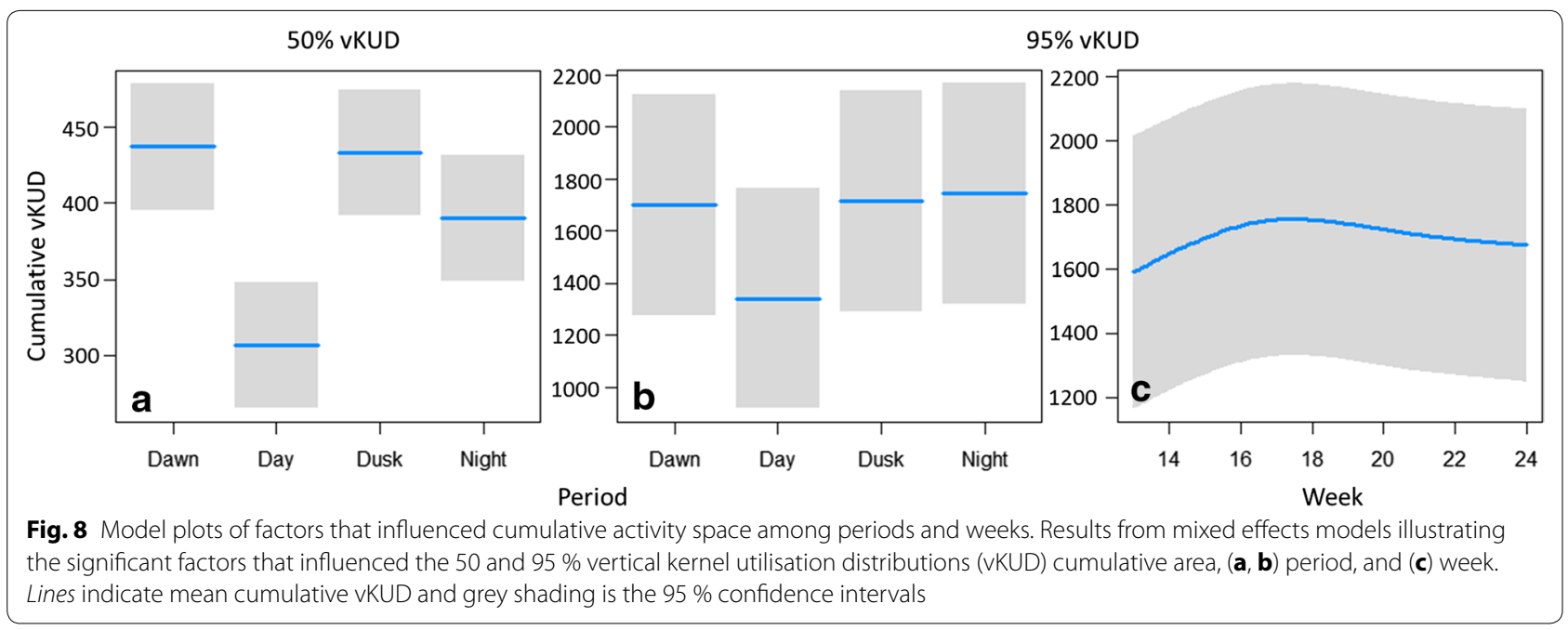

day and night hours, the strong patterns observed likely relate to nocturnal habits.

Horizontal and vertical space use for dawn, dusk and night periods was significantly larger than day periods, indicating larger areas are used, potentially as part of their foraging strategy. Although greater mobility and a larger night time space use could be expected for $L$. miniatus as a nocturnal predator, movements were not restricted to sandy habitat, as proposed by Currey et al. [8]. Instead, crepuscular and night hKUDs were spread across the monitored area, encompassing reef crest, slope and sandy regions. Patrolling large areas across habitat types could provide greater foraging opportunity among patches of sand between areas of coral cover in depths of greater than $7 \mathrm{~m}$. Analysis of paths of movement and tortuosity (e.g., [14]) would assist in elucidating evidence of feeding activity. Interestingly, individuals displayed relatively consistent depth use within the water column between reef crest and outer sand habitat, particularly for individuals with the most data (i.e. individuals 10155, 10162, 10170, 10154). For these benthic foragers [19], the lack of detections near deep sandy sediment (i.e., at $20 \mathrm{~m}+$ ) suggests 
this area may not have been used for foraging since individuals did not appear to be spending time near the benthos. Since this species occurs to depths $>100 \mathrm{~m}$ [20] and long-distance movements have been reported, the home range of these individuals likely extends further away from the reef crest than the monitored area. Thus, foraging areas may be located in deeper habitats further offshore and the observed midwater space use at the edge of the array may represent a midwater transit corridor. Shifts between daytime reef habitat for resting to sand habitat for foraging at night are common for haemulids [5, 21, 22], and like acanthurids that use landmarks, it is plausible that $L$. miniatus could visually follow bottom contours to deeper foraging areas nearby [23]. However, individuals used the monitored area during all periods of the day (including night). Therefore, movements to any habitats outside the acoustic array were interspersed with substantial time spent on and close to the reef.

During daylight hours, monitored L. miniatus spent most time along the reef slope to crest. This space use is consistent with that reported by Currey et al. [8]. These core areas along the reef were smaller in size than for hours of twilight or darkness, which corresponds with other studies in which less movement occurred during the day than in other periods, e.g., mullids, haemulids, and lutjanids [14, 24, 25]. Daytime horizontal core areas for $L$. miniatus were generally located within the areas used during other periods, like that for Kyphosus sectatrix [26]. Thus, horizontal core areas used during dawn, dusk and night periods were spatially separated from areas used during the day, which was more restricted along the reef. Vertical core areas were similar and only marginally shallower during the day than in other periods, and represented $29-37 \%$ of dawn, dusk and night areas by overlap. Coral reef fishes including mullids, scarids and acanthurids often display some degree of diel spatial separation in habitat use [16, 24, 27], and a greater amount of time spent over a smaller area by $L$. miniatus signifies the lifestyle of this species may incorporate resting during the day. The complexity of coral structure interspersed with sand on the Heron Island reef slope could be used for opportunistic foraging, or may also assist in daytime predator avoidance for L. miniatus, as has been observed for haemulids and lutjanids in the Caribbean [14]. For activity space extent, horizontal areas were similar in size along the reef during daytime, with significantly larger vertical areas used during crepuscular and night periods. However, like Plectropomus leopardus [28], movement within the water column substantially overlapped among periods, which may be an effect of the estimates incorporating movements across the monitoring period of $>3$ months, including potential temporal variability.
By examining vertical space use at a weekly temporal scale, stronger trends were observed through the monitoring period. Vertical space use extent fluctuated from the start of monitoring in March and peaked during the middle to end of each month (April, May and June) until the cessation of monitoring in towards the end of June. The amount of overlap in the extent of space use among weeks also displayed this trend, while core area overlap increased from March, peaked during the beginning of May, and decreased in size thereafter. Strong seasonal trends have been observed for other reef-associated fishes such as carangids, where shifts in core areas to spawning grounds occur during June to September [29]. While the proportion of mature L. miniatus females begins to increase in May within the region of the study site [30], spawning occurs on the Great Barrier Reef (GBR) between July and October, rendering this possibility as a cause for the observed pattern unlikely. High variability was evident in area and overlap among weeks, periods and individuals, which signifies that trends with time are unrelated to spawning or environmental drivers related to season. Alternatively, a strong correlation was observed between the monthly trend for increased home range extent and the weeks in which full moons occurred. Three expansions in vKUD area were demonstrated among all periods coinciding with moon illumination, and increased size of overall search areas during these phases may be necessary since higher luminosity may alter prey behaviour, making prey capture more difficult [31]. If larger home ranges during this moon phase are linked to a need to increase search area, this would explain the high degree of overlap in space use among periods. Although the relationship between lunar cycle and activity has not been investigated for reef fish, increased catch-per-unit-effort of pelagic fishes has been observed during full moon periods, indicating increased foraging activity during times of prey availability [32, 33]. The underlying relationship between activity space and moon luminosity has been observed for terrestrial carnivores [34] and presents a possible explanation for the temporal variation observed. Further research is required to link moon luminosity to space use and foraging behaviours in reef fishes.

Like the model results for space use overlap, cumulative vertical space use, or re-use of area, was variable with time. Cumulative core area was consistently high during crepuscular periods, suggesting that individuals reused the same large areas during dawn and dusk hours. Similarly, the smaller core daytime areas were revisited, and overall movement extent for all periods was relatively stable after the first few weeks of monitoring. Night areas in which individuals spent most time (core areas) appeared to increase in size through time, but it was the 
weekly difference in space extent which was significant, which implies increased travel to new areas and variability through time.

Fine-scale data revealed diel activity space use of $L$. miniatus which reflects a nocturnal lifestyle. Testing the hypothesis proposed by Currey et al. [8], it appears that monitored individuals occupied smaller areas on the reef slope during the day. Rather than simply shifting to deeper adjacent sandy areas during night, larger horizontal and vertical areas were used during crepuscular and night periods. While these patterns reflect a limited number of individuals, these trends were persistent and clear, particularly when incorporating temporal variation by examining vertical space use at a finer weekly scale. Understanding how animal behaviour and movements change temporally and spatially (among habitats) is important to understanding how species coexist within ecological niches [35, 36]. Insight into diel activity potentially related to foraging, predator avoidance or intraspecific competition can be gained through analysis at a finer-scale and enhanced resolution, which provided a better understanding of the ecology of this exploited species.

\section{Methods}

\section{Study site and sampling}

An array of Vemco VR2W ${ }^{\circledR}$ acoustic receivers deployed on the northern reef slope of Heron Island Reef $\left(23.4500^{\circ} \mathrm{S}, 151.9167^{\circ} \mathrm{E}\right)$, Capricorn-Bunker region of the GBR was utilised to monitor L. miniatus movements (Fig. 9). The study site included reef crest habitat, complex coral cover and coral bommies with sand patches on the reef slope, descending into sandy habitat, reaching approximately $40 \mathrm{~m}$ in depth in the northern channel. Ten receivers were deployed 22/3/2014-23/3/2014 on star pickets embedded in the substrate in two lines parallel to the reef crest, $<200 \mathrm{~m}$ in distance apart. Inner receivers were positioned close to the reef crest (5-12 m in depth) and outer receivers were positioned in sand habitats (18-21 $\mathrm{m}$ in depth).

Eleven adult $L$. miniatus were captured by line fishing using rod and reel (13.6 kg line and $27.2 \mathrm{~kg}$ leader) with barbless $8 / 0$ hooks baited with pilchard or squid on 22-23 March 2014. Excess gases from the swim bladder were released post-capture by venting, then individuals were anaesthetised with Aqui-S. A V13P ${ }^{\circledR}$ transmitter with pressure (depth) sensor (Vemco Ltd., Canada, 364 day battery life) was surgically implanted into the abdominal cavity via a small incision made longitudinally between the pectoral and ventral fins on the left side. The incision was closed by two simple interrupted stitches using absorbable sutures. Fish were released after a fork length (FL, in $\mathrm{mm}$ ) measurement was recorded, a dart tag (PDS; Hallprint ${ }^{\odot}$ ) for identification fitted externally and after recovery in fresh sea water (total procedure $<8 \mathrm{~min}$ ).

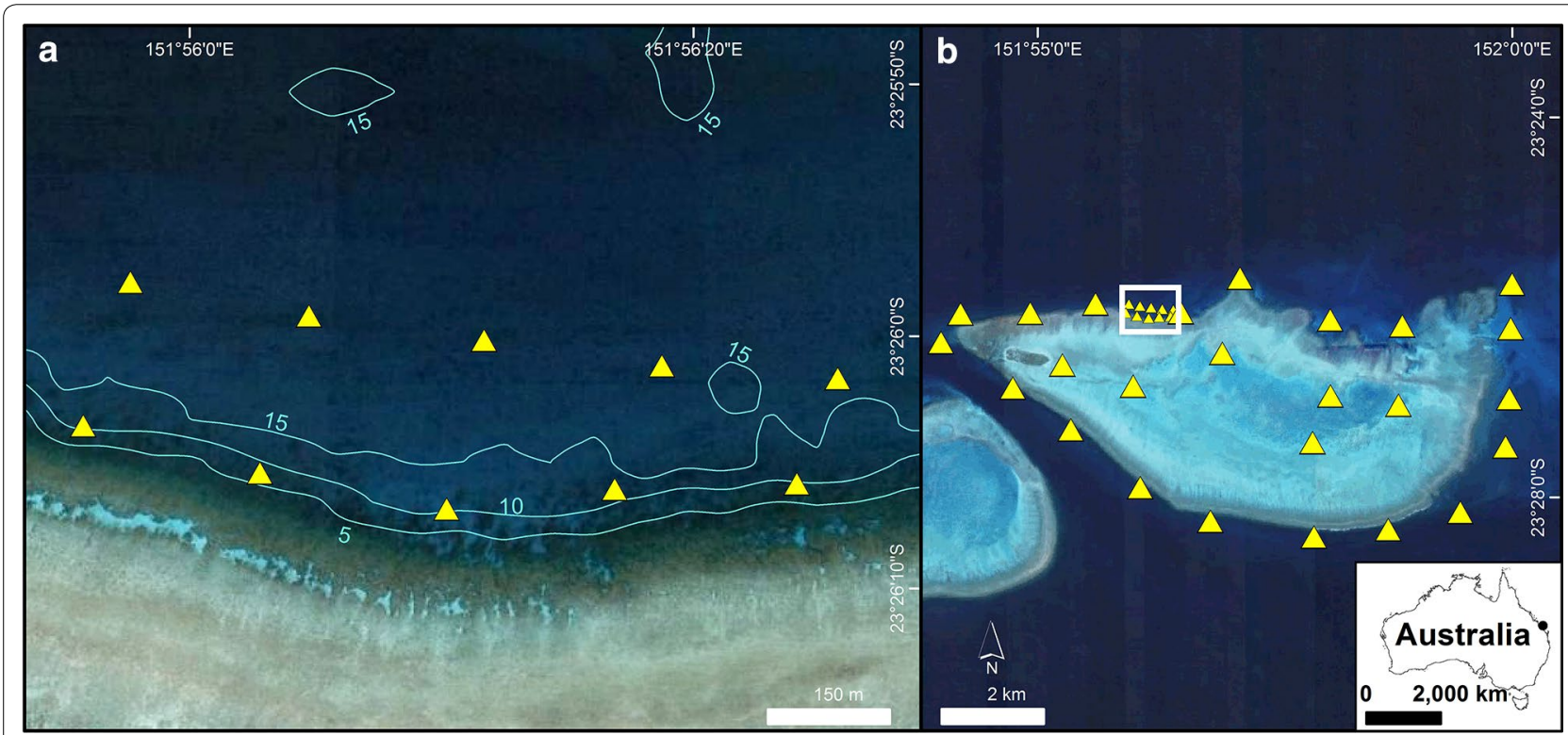

Fig. 9 Location of the study site on the north of Heron Island Reef, Australia. Acoustic receivers (yellow triangles) were deployed in two lines parallel to the reef crest across a depth gradient from those closest to the reef crest (inner) to outer receivers on the deeper reef slope (a). Contour lines indicate underwater bathymetry with depth $(\mathrm{m})$. The small-scale acoustic array $(\mathbf{a})$ was positioned within a larger array $(\mathbf{b})$ used in the previous study [8], as indicated by the white box. Inset indicates location on the east coast of Australia. Map data were generated from Hedley et al. [46, 47] 


\section{Data analysis}

Data from receivers were analysed in the $R$ environment version 3.1.0 [37]. Detection data were examined to identify any spurious detections, e.g. data that represented fast, erratic movements (i.e., consistent with fish consumed by predator), or lacked vertical movement aside from a consistent tidal signature (i.e., individual perished). Fish with these detection characteristics were assumed to have perished and were removed from analyses. Detections during the first $48 \mathrm{~h}$ were removed for all individuals to remove any effect of handling on fish behaviour. To test for variability in transmitter detection with time of day, mean detections of $L$. miniatus were standardised to mean detections of sentinel tags (deployed in the array during the monitoring period) per hour, according to Payne et al. [38]. Transmitters were detected when within distances of approximately $270 \mathrm{~m}$ from the receivers, determined by range testing at Heron Island Reef during a previous study [8].

For individuals detected for $>5$ days by two or more receivers, average positions were calculated at $10 \mathrm{~min}$ intervals [39]. To estimate diel individual space use, four discrete 3 -h periods were selected from the data to represent dawn, day, dusk and night. The 3-h duration was selected to enable sufficient data points for space use estimation and a balanced sampling design. The hours selected for dawn (0400-0659) and dusk (1700-1959) were based on timing of local sunrise, sunset and astro twilight calculated across the 3 months of monitoring. Since dawn and dusk behaviours typically occur over 1 hour of changing light [3], a portion of these $3 \mathrm{~h}$ periods would likely encompass day and night behaviours. Hours selected for day and night periods incorporated midnight and midday. Data for remaining hours were excluded as buffer periods.

Horizontal and vertical space use was estimated using kernel utilisation distributions (KUDs). Horizontal space use KUDs (hKUD; [40] ) were calculated using the adehabitat package in $\mathrm{R}$ [41]. Vertical KUDs (vKUD) were estimated using the ks package in $\mathrm{R}$ [42] in a linear twodimensional space to determine the vertical use of the water column perpendicular to the reef crest. The perpendicular distance between each acoustic receiver to the closest point on the reef crest was calculated, and since receivers were positioned between the reef crest and the sand, average positions were represented as the mean distance to crest by mean depth (similar to [8, 43]. Both space use estimates were calculated for core use areas (50\% KUD) and extent of activity space (95\% KUD). Data were screened for normality and homogeneity of variances.

Mixed effects models were used to determine whether differences in horizontal and vertical KUDs existed among time periods (dawn, day, dusk and night time periods) and individual fish size (FL). KUDs were treated as the response variable, period and FL were modelled as fixed factors and models were analysed using the nlme package in $\mathrm{R}$ [44]. Individual fish was treated as a random effects term to account for the lack of temporal and spatial independence among individuals and to reduce the effect of individuals with more detections. Mixed effects models were also used to determine whether there were differences in overlap of vertical KUDs among periods. Significance was assessed at the $p<0.05$ level.

For each period (dawn, day, dusk, night), comparisons in the size of vertical areas (50 and $95 \%$ vKUDs) through time were examined using mixed effects models. Response variables were square root transformed vKUD estimates (to satisfy assumptions of homogeneity of variance and normality), period and week were fixed factors, and individual fish ID was the random effects term. Week was fitted as a natural spline with varying degrees of freedom, with the best-fitting model compared using the Akaike Information Criterion corrected for small sample bias $\left(\mathrm{AIC}_{\mathrm{c}}\right)$.

To ascertain whether the 50 and $95 \%$ vKUDs covered the same locations for each time period through subsequent weeks, proportional overlap of areas from week to week were calculated. Overlap was represented as the proportion of the previous week's value, and values were arcsine transformed. Models were weighted by week using the varIdent variance structure to achieve homogeneous variances, since patterns in residual variance were found through time [45].

For each period (dawn, day, dusk and night), utilisation of new areas per week was examined using cumulative weekly activity space. Cumulative 50 and $95 \%$ vKUDs for consecutive weeks were calculated with position data from that week, and added to the positions of all previous weeks in an iterative manner [43]. The difference between the current and previous week's vKUD as a function of the previous week's value was calculated to identify whether individuals were using new areas with time. Models were weighted by week for $50 \%$ vKUD estimates only.

\section{Authors' contributions}

LMC developed the study, designed the study, conducted the fish sampling and data collection, carried out analyses, drafted and edited the manuscript. MRH provided project funding, designed the study, participated in fish sampling and commented on drafts of the manuscript. CAS assisted with fish sampling and analysis, and commented on drafts of the manuscript. AJW assisted with analysis and commented on drafts of the manuscript. All authors read and approved the final manuscript.

\section{Author details}

1'AIMS@JCU, James Cook University, Townsville, QLD 4811, Australia. ${ }^{2}$ Australian Institute of Marine Science, PMB No 3, Townsville, QLD 4810, Australia.

${ }^{3}$ Centre for Sustainable Tropical Fisheries and Aquaculture and College of Marine and Environmental Sciences, James Cook University, Townsville, QLD 
4811, Australia. ${ }^{4}$ Oceanic Fisheries Programme, Secretariat of the Pacific Community, BP D5, 98848 Noumea, New Caledonia.

\section{Acknowledgements}

We thank the staff and students of the Fishing and Fisheries Research Group for assisting with this project, particularly A Tobin, F de Faria, S Moore, E Lédée and P Yates. Infrastructure and field support provided by the Australian Animal Tagging and Monitoring System facility of the Integrated Marine Observing System and the Australian Institute of Marine Science was greatly appreciated. Maps were produced by E Lédée with data provided by R Beaman, the Commonwealth of Australia (Great Barrier Reef Marine Park Authority), $\mathrm{Google}^{\mathrm{TM}}$ earth and DigitalGlobe. Funding for this research was provided by the Australian Research Council awarded to MRH. Additional research funding was granted to LMC from James Cook University (JCU) School of Earth and Environmental Sciences (SEES). LMC was also supported by an AIMS@JCU Postgraduate Research Scholarship and stipend. All research activities were conducted under GBRMPA permit numbers G10/33754.1 and G10/33758.1 and Queensland Department of Agriculture, Fisheries and Forestry permit number 144482. Treatment of all animals was conducted under ethical guidelines approved by JCU animal ethics number A1566.

\section{Compliance with ethical guidelines}

\section{Competing interests}

The authors declare that they have no competing interests.

Received: 7 January 2015 Accepted: 11 September 2015

Published online: 29 September 2015

\section{References}

1. Sale PF. The ecology of fishes on coral reefs. New York: Academic Press; 1991.

2. Quinn TP, Brodeur RD. Intra-specific variations in the movement patterns of marine animals. Am Zool. 1991;31:231-41.

3. Hobson ES. Activity of Hawaiian reef fishes during the evening and morning transitions between daylight and darkness. Fish Bull. 1972;70:715-40.

4. Kozakiewicz M. Resource tracking in space and time. In: Hansson L, Fahrig $L$, Merriam G, editors. Mosaic Landscapes and Ecological Processes. London: Chapman and Hall; 1995. p. 136-48.

5. Appeldoorn RS, Aguilar-Perera A, Bouwmeester BLK, Dennis GD, Hill RL, Merten W, Recksiek CW, Williams SJ. Movement of fishes (Grunts: Haemulidae) across the coral reef seascape: a review of scales, patterns and processes. Caribb J Sci. 2009;45:304-16.

6. Holland KN, Lowe CG, Wetherbee BM. Movements and dispersal patterns of blue trevally (Caranx melampygus) in a fisheries conservation zone. Fish Res. 1996;25:279-92.

7. Dubin RE, Baker JD. Two types of cover-seeking behavior at sunset by the princess parrotfish, Scarus taeniopterus, at Barbados. West Indies. Bull Mar Sci. 1982;32:572-83.

8. Currey LM, Heupel MR, Simpfendorfer CA, Williams AJ. Sedentary or mobile? Variability in space and depth use of an exploited coral reef fish. Mar Biol. 2014;161:2155-66.

9. Carpenter KE. Lethrinidae. Emperor (emperor snappers). In: Carpenter $\mathrm{KE}$, Niem $\mathrm{V}$, editors. FAO species identification guide for fishery purposes The living marine resources of the Western Central Pacific Volume 5 Bony fishes part 3 (Menidae to Pomacentridae). Rome: FAO; 2001. p. 3004-51.

10. Carpenter KE, Allen GR. FAO Species Catalogue Vol. 9. Emperor fishes and large-eye breams of the world (family Lethrinidae). An annotated and illustrated catalogue of lethrinid species known to date. FAO Species Synop. No. 9. 1989.

11. Holland KN, Peterson JD, Lowe CG, Wetherbee BM. Movements, distribution and growth rates of the white goatfish Mulloides flavolineatus in a fisheries conservation zone. Bull Mar Sci. 1993;52:982-92.

12. Willis TJ, Badalamenti F, Milazzo M. Diel variability in counts of reef fishes and its implications for monitoring. J Exp Mar Biol Ecol. 2006;331:108-20.

13. Fox RJ, Bellwood DR. Unconstrained by the clock? Plasticity of diel activity rhythm in a tropical reef fish. Siganus lineatus. Funct Ecol. 2011;25:1096-105.
14. Hitt S, Pitman SJ, Nemeth RS. Diel movements of fishes linked to benthic seascape structure in a Caribbean coral reef ecosystem. Mar Ecol Prog Ser. 2011;427:275-91.

15. Hobson ES. Feeding patterns among tropical reef fishes: understanding the way fishes respond to changing conditions during the day-night cycle provides insight into their feeding activities. Am Sci. 1975;63:382-92

16. Howard KG, Claisse JT, Clark TB, Boyle K, Parrish JD. Home range and movement patterns of the Redlip Parrotfish (Scarus rubroviolaceus) in Hawaii. Mar Biol. 2013;160:1583-95.

17. Mazeroll Al, Montgomery WL. Structure and organization of local migrations in brown surgeonfish (Acanthurus nigrofuscus). Ethology. 1995;99:89-106.

18. Pitcher TJ, Turner JR. Danger at dawn: experimental support for the twilight hypothesis in shoaling minnows. J Fish Biol. 1986;29:59-70.

19. Walker MH. Food and feeding habits of Lethrinus chrysostomus Richardson (Pisces : Perciformes) and other lethrinids on the Great Barrier Reef. Aust J Mar Freshw Res. 1978;29:623-30.

20. Newman SJ, Williams DM. Variation in reef associated assemblages of the Lutjanidae and Lethrinidae at different distances offshore in the central Great Barrier Reef. Environ Biol Fishes. 1996;46:123-38.

21. Ogden JC, Ehrlich PR. The behavior of heterotypic resting schools of juvenile grunts (Pomadasyidae). Mar Biol. 1977;42:273-80.

22. Tulevech SM, Recksiek CW. Acoustic tracking of adult white grunt, Haemulon plumieri, in Puerto Rico and Florida. Fish Res. 1994;19:301-19.

23. Mazeroll Al, Montgomery WL. Daily migrations of a coral reef fish in the Red Sea (Gulf of Aqaba, Israel): initiation and orientation. Copeia. 1998;1998:893-905.

24. Meyer CG, Holland KN, Wetherbee BM, Lowe CG. Movement patterns, habitat utilization, home range size and site fidelity of whitesaddle goatfish, Parupeneus porphyreus, in a marine reserve. Environ Biol Fishes. 2000;59:235-42

25. Topping DT, Szedlmayer ST. Home range and movement patterns of red snapper (Lutjanus campechanus) on artificial reefs. Fish Res. 2011;112:77-84

26. Eristhee N, Oxenford HA. Home range size and use of space by Bermuda chub Kyphosus sectatrix (L.) in two marine reserves in the Soufriere Marine Management Area, St Lucia, West Indies. J Fish Biol. 2001;59:129-51.

27. Meyer CG, Papastamatiou YP, Clark TB. Differential movement patterns and site fidelity among trophic groups of reef fishes in a Hawaiian marine protected area. Mar Biol. 2010;157:1499-511.

28. Zeller DC. Home range and activity patterns of the coral trout Plectropomus leopardus (Serranidae). Mar Ecol Prog Ser. 1997;154:65-77.

29. Afonso P, Fontes J, Holland KN, Santos RS. Multi-scale patterns of habitat use in a highly mobile reef fish, the white trevally Pseudocaranx dentex and their implications for marine reserve design. Mar Ecol Prog Ser. 2009;381:273-86

30. Williams AJ, Davies CR, Mapstone BD. Regional patterns in reproductive biology of Lethrinus miniatus on the Great Barrier Reef. Mar Freshw Res. 2006;57:114-403.

31. Hobson ES. Diel feeding migrations in tropical reef fishes. Helgolainder wiss Meeresunters. 1973;24:361-70.

32. Poisson F, Gaertner J-C, Taquet M, Durbec J-P, Bigelow K. Effects of lunar cycle and fishing operations on longline-caught pelagic fish: fishing performance, capture time and survival of fish. Fish Bull. 2010;108:268-81.

33. Shimose T, Yokawa K, Tachihara K. Higher catch rates around the full moon for blue marlin, Makaira nigricans, in a diurnal trolling fishery. Bull Mar Sci. 2013;89:759-65.

34. Cozzi G, Broekhuis F, McNutt JW, Turnbull LA, Macdonald DA, Schmid B. Fear of the dark or dinner by moonlight? Reduced temporal partitioning among Africa's large carnivores. Ecology. 2012;93:2590-9.

35. Bosiger YJ, McCormick MI. Temporal links in daily activity patterns between coral reef predators and their prey. PLoS One. 2014;9:e111723.

36. Kronfeld-Schor N, Dayan T. Partitioning of time as an ecological resource. Annu Rev Ecol Syst. 2003;34:153-81.

37. R Development Core Team. A language and environment for statistical computing. Vienna: R Foundation for Statistical, Computing; 2014.

38. Payne NL, Gillanders BM, Webber DM, Semmens JM. Interpreting diel activity patterns from acoustic telemetry: the need for controls. Mar Ecol Prog Ser. 2010;419:295-301. 
39. Simpfendorfer CA, Heupel MR, Hueter RE. Estimation of short-term centers of activity from an array of omnidirectional hydrophones and its use in studying animal movements. Can J Fish Aquat Sci. 2002;59:23-32.

40. Heupel MR, Simpfendorfer CA, Heuter RE. Estimation of shark home ranges using passive monitoring techniques. Environ Biol Fishes. 2004;71:135-42

41. Calenge $C$. The package adehabitat for the R software: tool for the analysis of space and habitat use by animals. Ecol Model. 2006;197:516-9.

42. Duong T. ks: Kernel density estimation and kernel discriminant analysis for multivariate data in R. J Stat Softw. 2007;21:1-16.

43. Heupel MR, Simpfendorfer CA. Importance of environmental and biological drivers in the presence and space use of a reef-associated shark. Mar Ecol Prog Ser. 2014;496:47-57.
44. Pinheiro J, Bates D, DebRoy S, Sarkar D, R Development Core Team. nlme: Linear and nonlinear mixed effects models. R package version 3.1-109. 2013.

45. Zuur AF, leno EN, Walker N, Saveliev AA, Smith GM. Mixed effects models and extensions in ecology with R. New York: Springer; 2009.

46. Hedley J, Roelfsema C, Phinn SR. Efficient radiative transfer model inversion for remote sensing applications. Rem Sens Environ. 2009;113:2527-32.

47. Hedley J, Roelfsema C, Phinn SR: Propagating uncertainty through a shallow water mapping algorithm based on radiative transfer model inversion. 20th Ocean Optics Conference, 27 Sep-1 Oct, 2010.
Submit your next manuscript to BioMed Central and take full advantage of:

- Convenient online submission

- Thorough peer review

- No space constraints or color figure charges

- Immediate publication on acceptance

- Inclusion in PubMed, CAS, Scopus and Google Scholar

- Research which is freely available for redistribution

Submit your manuscript at

www.biomedcentral.com/submit

() BioMed Central 